\title{
Protection of Anthocyanin from Myrica rubra against Cerebral Ischemia-Reperfusion Injury via Modulation of the TLR4/NF-KB and NLRP3 Pathways
}

\author{
Hong-Xin Cui ${ }^{1,2}$, Ji-Hong Chen ${ }^{1}$, Jing-Wan Li ${ }^{3}$, Fang-Rong Cheng ${ }^{1}$ and Ke Yuan ${ }^{4, *}$ \\ 1 College of Pharmacy, Henan University of Chinese Medicine, Zhengzhou 450046, China; \\ cuihongxin1974@163.com (H.-X.C.); chenjihong0011@163.com (J.-H.C.); \\ chengfangrong1963@126.com (F.-R.C.) \\ 2 Collaborative Innovation Center for Respiratory Disease Diagnosis and Treatment \& Chinese Medicine \\ Development of Henan Province, Zhengzhou 450046, China \\ 3 Forestry and biotechnology College, Zhejiang Agriculture and Forestry University, Lin'an 311300, China; \\ lijingwan127@126.com \\ 4 Jiyang College of Zhejiang Agriculture and Forestry University, Zhu'ji 311800, China \\ * Correspondence: yuan_ke001@163.com
}

Received: 19 June 2018; Accepted: 18 July 2018; Published: 20 July 2018

\begin{abstract}
Myrica rubra (MR) is rich in anthocyanins, and it has good anti-cancer, anti-aging, antioxidant, and antiviral effects. The proportion of disability and death caused by ischemic stroke gradually increased, becoming a major disease that is harmful to human health. However, research on effects of anthocyanin from MR on cerebral ischemia-reperfusion (I/R) injury is rare. In this study, we prepared eight purified anthocyanin extracts (PAEs) from different types of MR, and examined the amounts of total anthocyanin (TA) and cyanidin-3-O-glucoside (C-3-G). After one week of PAE treatment, the cerebral infarction volume, disease damage, and contents of nitric oxide and malondialdehyde were reduced, while the level of superoxide dismutase was increased in I/ $R$ mice. Altogether, our results show that Boqi ${ }^{1}$ MR contained the most TA $(22.07 \%)$ and C-3-G (21.28\%), and that PAE isolated from Dongkui MR can protect the brain from I/R injury in mice, with the mechanism possibly related to the Toll-like receptor 4 (TLR4)/ nuclear factor- $\mathrm{kB}$ (NF- $\mathrm{kB}$ ) and NOD-like receptor pyrin domain-containing 3 protein (NLRP3) pathways.
\end{abstract}

Keywords: Myrica rubra; anthocyanins; cyanidin-3-O-glucoside; cerebral ischemia-reperfusion; TLR4/NF-KB; NLRP3

\section{Introduction}

Stroke is one of the most common causes of adult disability and death worldwide, with more than $80 \%$ of all cases triggered by ischemic events. Stroke exhibits characteristics such as acute onset, unpredictability, high incidence, and presence in younger patients. Ischemic stroke typically results from thrombotic occlusion of the cerebral basilar artery (mostly the middle cerebral artery) or its branches [1,2]. The mechanism of ischemic cerebrovascular disease is complicated and multifactorial. At present, many drugs induce numerous side effects at the same time as exerting their therapeutic effect [3]. Therefore, it is vital to identify natural plant extracts that improve the current treatment status of cerebral ischemia-reperfusion (I/R) injury, to identify molecular biological mechanisms, and to investigate more effective treatment methods.

The Myricaceae plant, Myrica rubra Sieb. et Zucc., has a long cultivation history and a high yield in China, and is one of the most important edible fruits with a high anthocyanin content. Anthocyanins are prominent members of the secondary plant metabolite class of flavonoid compounds, which belong to 
the superfamily of antioxidants named phenolics or polyphenolics [4]. Anthocyanins are derivatives of the 2-phenyl-cationic structure, with a typical flavone structure formed from the combination of glycosidic bonds with anthocyanin. Along with chlorophyll and carotenoid, they are known as the three major natural pigments, and can be divided into six main anthocyanin groups according to their substituent groups (Figure 1). Among them, cyanidin-3-O-glucoside (C-3-G) is one of the most common anthocyanins, and accounts for $>95 \%$ of the total anthocyanin (TA) in Myrica rubra (MR) [5]. Many researchers showed that anthocyanins are beneficial, demonstrating antioxidant, anti-fatigue, anti-inflammatory, anti-carcinogenic, and anti-angiogenic properties [6-10]. The beneficial effects of anthocyanin on cerebral ischemia are well established. However, there are very few reports about MR's effects on cerebral I/R injury. Furthermore, the related mechanisms of the Toll-like receptor 4 (TLR4)/nuclear factor- $\mathrm{KB}$ (NF- $\mathrm{kB}$ ) and NOD-like receptor pyrin domain-containing 3 protein (NLRP3) pathways are still unreported. Thus, we prepared and analyzed eight kinds of purified anthocyanin extracts (PAEs) from different varieties of MR, studied their protection and mechanism with regards to cerebral I/R injury, and provided a theoretical basis for daily life and clinical research.

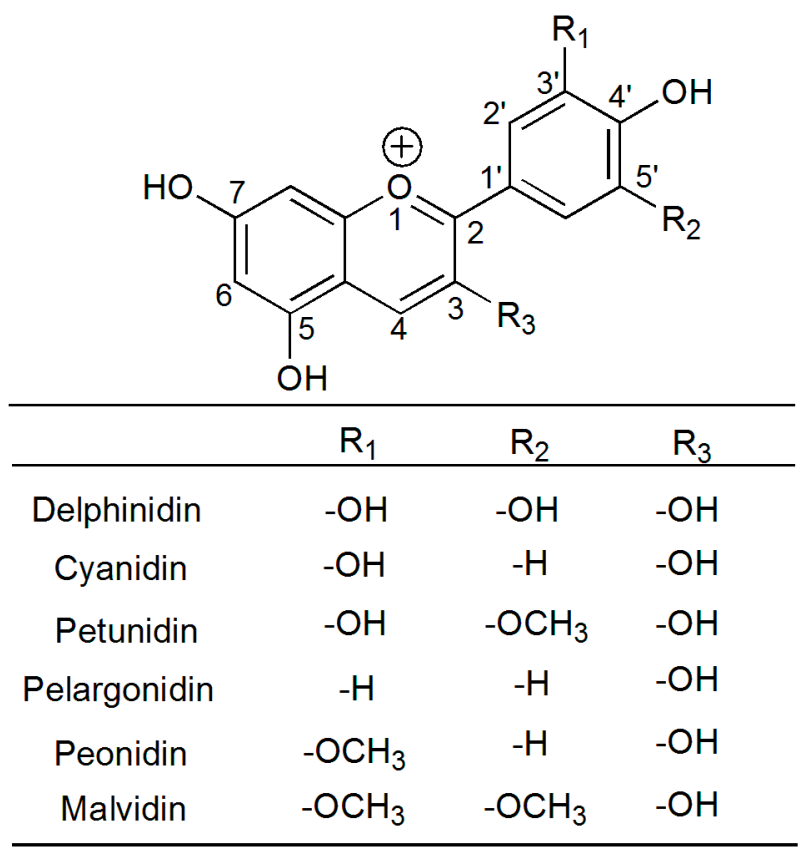

Figure 1. Structure of anthocyanidins.

\section{Materials and Methods}

\subsection{Materials and Reagents}

Eight cultivars of Myrica rubra were obtained from the Zhejiang Province, China in June 2016. Myrica rubra Sieb. et Zucc. cv. Biqi ${ }^{1}$, Myrica rubra Sieb. et Zucc. cv. Tanmei, and Myrica rubra Sieb. et Zucc. cv. Shuijing were obtained from Ninghai; Myrica rubra Sieb. et Zucc. cv. Biqi ${ }^{2}$ was obtained from Yuyao; Myrica rubra Sieb. et Zucc. cv. Dongkui was obtained from Taizhou; Myrica rubra Sieb. et Zucc. cv. Dingdai was obtained from Wenzhou; Myrica rubra Sieb. et Zucc. cv. Wandao was obtained from Zhoushan; and a wild species of Myrica rubra Sieb. et Zucc. was obtained from Lin'an. Fruits of each cultivar were stored at $-20^{\circ} \mathrm{C}$ until analysis.

Methanol, triphenyl tetrazolium chloride (TTC), and C-3-G standards were purchased from the Aladdin reagent company (Shanghai, China), while the nitric oxide (NO) kit, malondialdehyde (MDA) kit, and superoxide dismutase (SOD) kit were purchased from Nanjing Biological Science and Technology Co., Ltd. (Nanjing, China). The methanol purity was chromatography grade, and the other organic solvents and chemical reagents were analytically pure. 


\subsection{Animals}

Male ICR mice weighing $16-20 \mathrm{~g}$ were adapted to experimental conditions at $20 \pm 2{ }^{\circ} \mathrm{C}$, a humidity of $60 \pm 5 \%$, a 12-h light/dark cycle, and ad libitum access to food and water. Mice and food were purchased from the Laboratory Animal Center of the Zhejiang Academy of Medical Sciences (Hangzhou, China; Certificate Number SCXK 2014-0001). All procedures for animal experiments were in accordance with the guidelines of Chinese animal care, which conform with the international acceptance of the use of experimental animals.

\subsection{Preparation of PAEs}

Approximately $500 \mathrm{~g}$ of MR of each cultivar was denucleated and mashed. The flesh was extracted twice with a ratio of 1:2 $(\mathrm{v} / \mathrm{v})$ at a $\mathrm{pH} 3$ with a $50 \%$ ethanol solution using ultrasonic extraction for $1 \mathrm{~h}$, before being subjected to a rotary evaporator under vacuum at $40^{\circ} \mathrm{C}$ until the ethanol was completely evaporated. Then, it was passed through a resin column (Diaion, HP 2 MGL, Mitsubishi Co., Tokyo, Japan, $6 \mathrm{~cm} \times 30 \mathrm{~cm}$ ) depending on the adsorbent capability of each resin. C-3-G was adsorbed onto the column, while sugar, acids, and other water-soluble compounds were eluted with more than two BV (bed volume) of distilled water until the water was clear [11]. The adsorbed material was then eluted with acidified $60 \%$ ethanol $(v / v, \mathrm{pH} 3)$. The eluent was concentrated on a rotary evaporator at $40^{\circ} \mathrm{C}$, before the pigment powder was prepared and stored in a cool dry place until analysis (Figure 2).
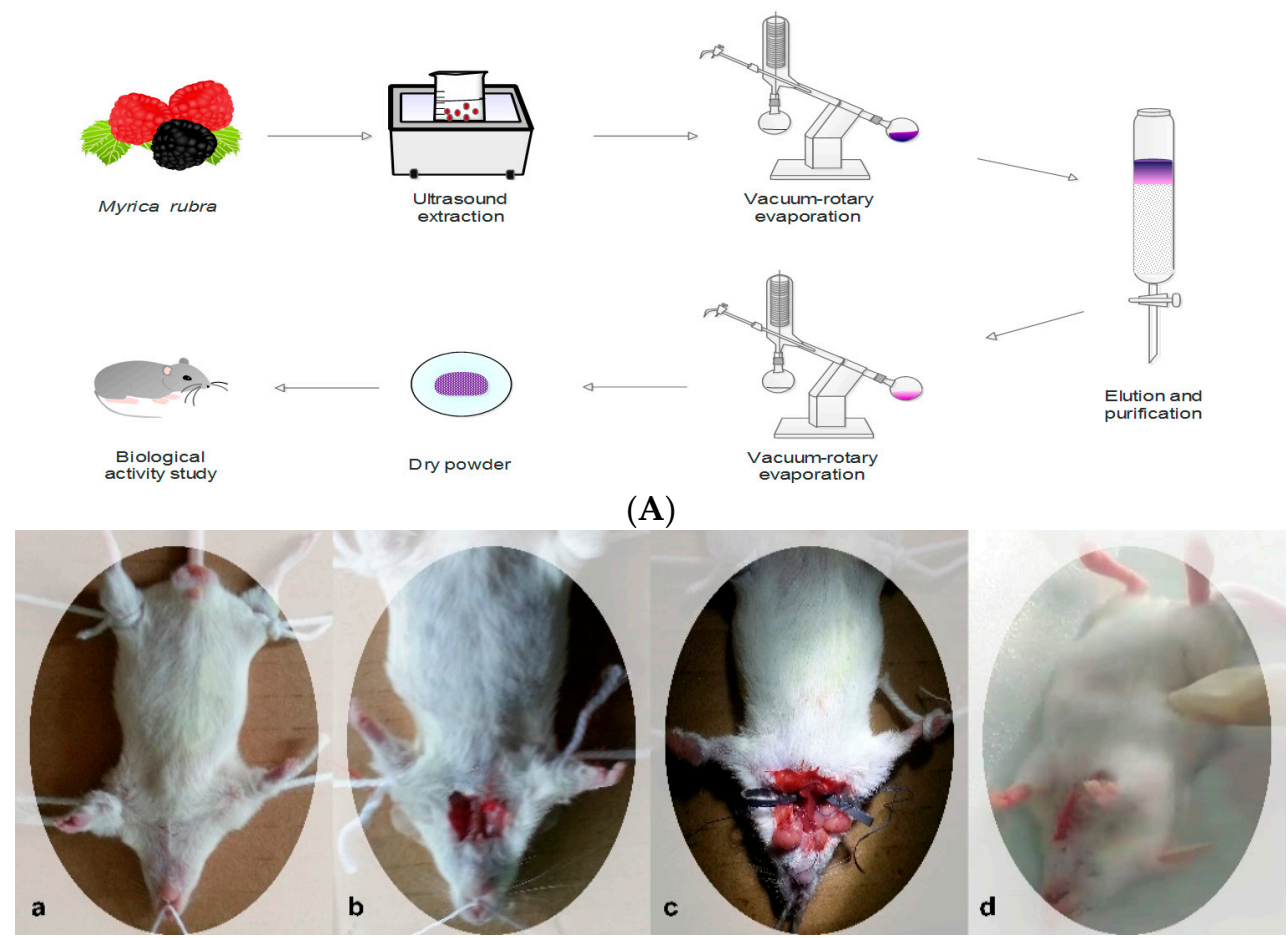

(B)

Figure 2. Experimental flow chart. (A) Process flow chart for the extraction and purification of total anthocyanin. (B) Experimental process of inducing cerebral ischemia-reperfusion (I/R) injury in mice: (a) anesthesia and fixation; (b) exposure of the common carotid arteries; (c) blocking of the blood circulation; (d) suture and recovery.

\subsection{Determination of TA in PAEs Using the $p H$ Difference Method}

A buffer solution of $\mathrm{pH} 1.0$ was prepared by mixing potassium chloride $(\mathrm{KCl})$ solution with $0.2 \mathrm{M}$ hydrochloric acid at a ratio of 25:67. The $\mathrm{pH}$ value was adjusted with the $\mathrm{KCl}$ solution. A buffer solution of $\mathrm{pH} 4.5$ was prepared by modifying the $\mathrm{pH}$ value of sodium acetate with hydrochloric 
acid. Eight types of PAE were dissolved with 50\% diluted alcohol, and were fixed with the buffer solutions of $\mathrm{pH} 1.0$ and $\mathrm{pH}$ 4.5. After incubating for $1 \mathrm{~h}$ in the dark, absorbance was measured using a UV-2102 PCS UV spectrophotometer (Shanghai UNICO Co., Ltd., Shanghai, China). Absorbance (A) was calculated as follows: $\mathrm{A}=(\mathrm{A} 510 \mathrm{~nm}$ pH $1.0-\mathrm{A} 700 \mathrm{~nm} \mathrm{pH} 1.0)-(\mathrm{A} 510 \mathrm{~nm} \mathrm{pH} 4.5-\mathrm{A} 700 \mathrm{~nm}$ $\mathrm{pH} 4.5)$. The formula for TA content was, $\mathrm{TA}(w / w)=(\mathrm{A} \times \mathrm{M} \times \mathrm{DF} \times \mathrm{V}) /\left(\varepsilon \times \mathrm{L} \times \mathrm{W}_{\mathrm{t}}\right)$, where $\mathrm{M}$ is the molecular weight, $\mathrm{DF}$ is the dilution factor, $\mathrm{V}$ is the volume, $\varepsilon$ is the extinction coefficient, $\mathrm{L}$ is the optical path, and $\mathrm{W}_{\mathrm{t}}$ is the fruit weight.

\subsection{Determination of C-3-G in PAEs Using HPLC}

The C-3-G content was analyzed using a Waters 2695 high-performance liquid chromatograph linked to a Waters 2996 photodiode array detector. All samples were filtered through a $0.45-\mu \mathrm{m}$ Millipore membrane filter before injection. A $10-\mu \mathrm{L}$ aliquot was separated using a SunFire-C18 column $\left(250 \mathrm{~mm} \times 4.6 \mathrm{~mm}, 5 \mu \mathrm{m}\right.$; Waters, Milford, MA, USA) at $30^{\circ} \mathrm{C}$. The mobile phase consisted of solvent A ( $2 \%$ hydrochloric acid in methyl alcohol) and solvent B (water, methyl alcohol, acetonitrile, and acetic acid at a ratio of 160:90:90:40, $v / v / v / v)$. Using an isocratic elution with the ratio of A:B as 93:7 at a flow rate of $1.0 \mathrm{~mL} / \mathrm{min}$, the $\mathrm{C}-3-\mathrm{G}$ content was detected at $530 \mathrm{~nm}$.

\subsection{Grouping}

All mice were randomly divided into five groups $(n=10)$ as follows: normal control (NC), treated with a saline solution and a sham operation; I/R, treated with a saline solution and cerebral ischemia-reperfusion injury; and PAE 100, PAE 150, and PAE 300, treated with $100 \mathrm{mg} / \mathrm{kg}$, $150 \mathrm{mg} / \mathrm{kg}$, and $300 \mathrm{mg} / \mathrm{kg}$ PAE, respectively, from Dongkui Myrica rubra every day, as well as cerebral ischemia-reperfusion injury. Intragastric administration was done for seven days, and all mice were free to eat during the experiment.

\subsection{Cerebral I/R Injury}

One hour after the final administration, the mice were anesthetized and fixed to a surgical platform. A neck disinfection was performed, followed by a blunt separation at the median incision to expose the right common carotid artery, external carotid artery, and internal carotid artery. The right external carotid artery was isolated and coagulated. Artery clamps were inserted into the internal carotid artery via the external carotid artery until they reached the bifurcation of the right middle cerebral artery and the anterior cerebral artery, so as to block the blood circulation in the right middle cerebral artery. The block was applied to the mice for $15 \mathrm{~min}$, before the application of a 10-min perfusion; this process was repeated four times. The wounds were sutured after being blocked for up to $2 \mathrm{~h}$. The mice in the normal control group underwent the operation with suturing only and no artery clipping. The mice recovered for $24 \mathrm{~h}$, and blood was taken from the eyeball, while the brain tissue was rapidly removed (Figure 2).

\subsection{Neurological Deficit Scores}

Twenty-four hours after reperfusion, the neurological deficits of the mice were assessed and scored using the Bederson neurological scale [12]. The scores were recorded as follows: 0, no neurological deficit; 1 , failure to fully extend left forepaw or to flex contralateral torso and forelimb; 2 , reduced resistance to lateral push or circling to the left side when the mouse was held by the tail on a flat surface, despite the posture of the mouse being normal at rest; 3 , spontaneous circling to the left; and 4 , absence of spontaneous movement or unconsciousness.

\subsection{Determination of Infarct Volume in Brain Tissue}

The brain tissue was cut into five slices (approximately 2-mm-thick) and dyed with $2 \%$ triphenyl tetrazolium chloride (TTC) for $30 \mathrm{~min}$ at $37^{\circ} \mathrm{C}$. The stained brain sections were fixed with $4 \%$ 
paraformaldehyde. Normal brain tissue goes brick-red, while infarcted areas remain unstained [13]. The infarct volume was calculated using the Image J software (V2.1.4.7, Bethesda, Rockville, MD, USA). Cerebral infarction volume $(\%)=$ infarct volume/total section volume $\times 100$.

\subsection{Monitoring of NO, SOD, and MDA Levels}

The brain tissue of the mice was removed and immediately homogenized. The volume of the brain tissue homogenates at a volume fraction of $10 \%$ were obtained using a ratio of $1: 9$ to the volume of normal saline. The contents of NO, SOD, and MDA in brain tissue were detected using the appropriate kits.

\subsection{Histopathology}

At the end of the experiment, the brain tissue was promptly excised from the animals, who were anesthetized with $4 \%$ chloral hydrate solution. The organs were rinsed with normal saline and were fixed in 10\% neutral-buffered formalin for histopathological examination using hematoxylin and eosin staining.

\subsection{Western Blotting}

Total protein was extracted from the same position of the ischemic side of the mouse's cerebral cortex using a commercial kit (Aidlab Biotechnologies Co. Ltd., Beijing, China). For Western-blot analysis, equal amounts of protein ( $50 \mu \mathrm{g}$ per lane) were loaded in the wells of $12 \%$ polyacrylamide gels. After the electrophoretic run, the proteins were electrotransferred onto polyvinylidene fluoride (PVDF) membranes. Then, the membranes were incubated for $2 \mathrm{~h}$ in blocking buffer $[1 \times$ TBS (Tris buffer solution), $0.1 \%$ Tween 20 , and $4 \%$ nonfat milk] at room temperature. All membranes were incubated in a primary-antibody solution overnight at $4{ }^{\circ} \mathrm{C}$, and then, in a secondary-antibody solution for $2 \mathrm{~h}$ at room temperature. The primary-antibody dilutions were anri-TLR4 (1:500), anti-tumor necrosis factor alpha (TNF- $\alpha$; 1:500), anti- nuclear erythroid 2-related factor 2 (Nrf2; 1:1000), anti-caspase-1 (1:1000), anti-NLRP3 (1:1000), and IL-18 (1:1000) (Boster Biological Technology Ltd., Wuhan, China). The membranes were washed three times for $5 \mathrm{~min}$, and were incubated for $2 \mathrm{~h}$ at $4{ }^{\circ} \mathrm{C}$ with HRP-conjugated (horseradish peroxidase-conjugated) secondary antibodies (anti-rabbit and anti-mouse; Boster Biological Technology Ltd., Wuhan, China). The density of the bands was determined using an enhanced chemiluminescence detection system (Amersham Pharmacia, Piscataway, NJ, USA), and the gray value of the bands were quantified using the ImageJ analysis software.

\subsection{Statistical Analysis}

All data are expressed as mean \pm standard deviation, and were analyzed using the SPSS statistical software (SPSS19.0 Inc., Chicago, IL, USA). One-way analysis of variance (ANOVA) with a Duncan's test were used for inter-group comparisons. A $p$-value $<0.05$ was considered as statistically significant, and a $p$-value $<0.01$ was considered as highly significant.

\section{Results and Discussion}

\subsection{TA and C-3-G Contents in the Eight Varieties of $M R$.}

MR is rich in anthocyanins, with $>95 \%$ being C-3-G [5,14]. Anthocyanins are phenolic compounds, and various types of stress (e.g., ultraviolet radiation, pathogens, soil, sunlight, rainfall, genetic factors, germination, maturity, and species diversity) can influence their levels [15,16].

From Table 1 and Figure 3, it is apparent that, in addition to Shuijing, the other seven types of MR contained anthocyanins, with obvious differences in content. Among them, Boqi ${ }^{1}$ MR contained the most TA $(22.07 \%)$ and C-3-G (21.28\%), which is consistent with previous findings [5]. In general, 
the anthocyanin content in MR was closely related to the variety, while the same species were not affected by region.

Table 1. The levels of purified anthocyanin extracts (PAEs), and the total anthocyanin (TA) and cyanidin-3-O-glucoside (C-3-G) contents in PAEs from eight cultivars of Myrica rubra.

\begin{tabular}{cccc}
\hline Varieties & PAE & TA & C-3-G \\
\hline Boqi $^{1}$ & $0.38 \%$ & $22.07 \%$ & $21.28 \%$ \\
Tanmei & $0.40 \%$ & $8.77 \%$ & $8.59 \%$ \\
Shuijing $^{\text {Boqi }}{ }^{2}$ & $0.00 \%$ & $0.00 \%$ & $0.00 \%$ \\
Dongkui $_{\text {Dingdai }}$ & $0.24 \%$ & $18.95 \%$ & $18.57 \%$ \\
Wandao & $0.32 \%$ & $18.10 \%$ & $17.41 \%$ \\
Wild & $0.38 \%$ & $12.56 \%$ & $11.79 \%$ \\
\hline
\end{tabular}

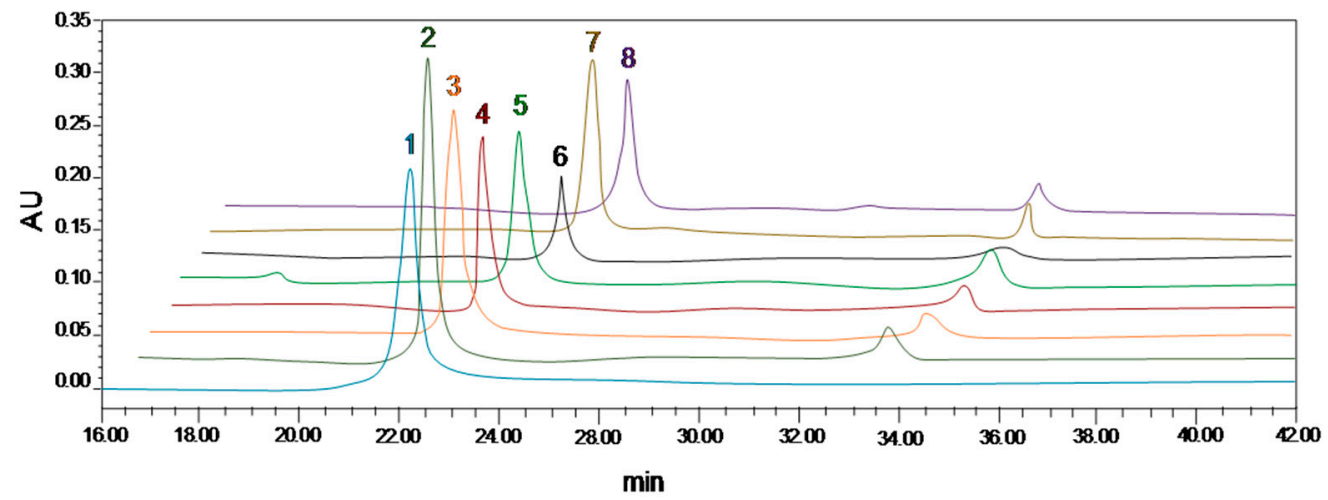

Figure 3. HPLC results for cyanidin-3-O-glucoside (C-3-G) in purified anthocyanin extracts. 1, C-3-G standard; 2, Boqi ${ }^{1}$; 3, Boqi ${ }^{2}$; 4, Wandao; 5, Dingdai; 6, Wild; 7, Dongkui; 8, Tanmei.

The fruit of Dongkui MR weighs 20-25 grams, with the fruit being purple, as well as having a thicker cinnamon, soluble solid content of $13.5 \%$, and a sugar content of $10.5 \%$. Furthermore, it is of high and stable yield, and is wind-resistant, with mature fruits that do not fall easily. Moreover, in recent years, all localities promoted its planting. Therefore, this study investigated Dongkui MR, and examined the role of PAEs in the protection against cerebral I/ $R$ in mice, and their mechanism of action.

\subsection{Effect of PAEs on Neurological Deficits and on Cerebral Infarct Volumes in Experimental Mice}

Currently, ischemic cerebrovascular disease is one of the most important diseases threatening human health and survival. Reperfusion injury is also a major concern in the treatment of ischemic cerebrovascular disease. The middle cerebral artery is a vulnerable region in clinical ischemic cerebrovascular disease. Among patients with cerebral infarction, the proportion with trunk infarction of the middle cerebral artery was $82.12 \%$ [17]. Therefore, the model of middle cerebral artery I/R induced by internal carotid artery occlusion is the closest to a clinical lesion. As shown in Figure 4, the results of the evaluation of neurological function in mice showed that the brain-nerve injury in $I / R$ mice was significantly greater than that in the NC group $(p<0.01)$. After PAE treatment, the injury was reduced, especially in the middle- and high-dose groups $(p<0.01)$. The cerebral infarct volume was detected using TTC staining. The NC group had no infarction. Compared with the NC group, the cerebral I/R injury in the I/R group was associated with obvious infarction $(p<0.05)$. Additionally, the cerebral infarct volume in mice treated with PAEs was significantly smaller when compared with that of the I/R group ( $p<0.05)$, especially in the PAE 150 and PAE 300 groups $(p<0.01)$. 
A

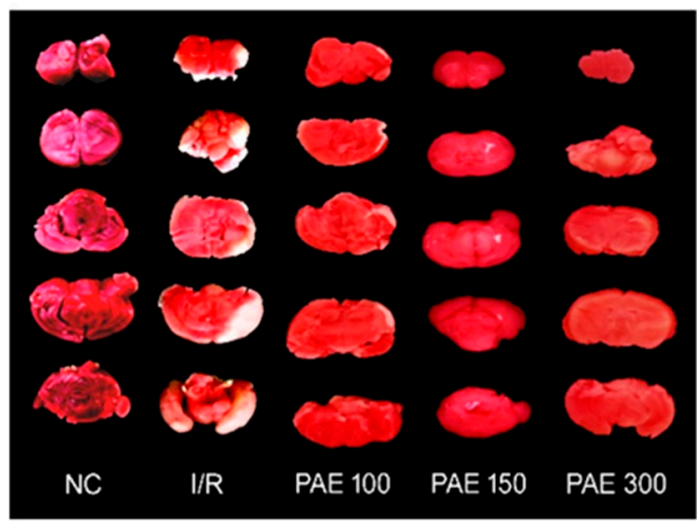

B

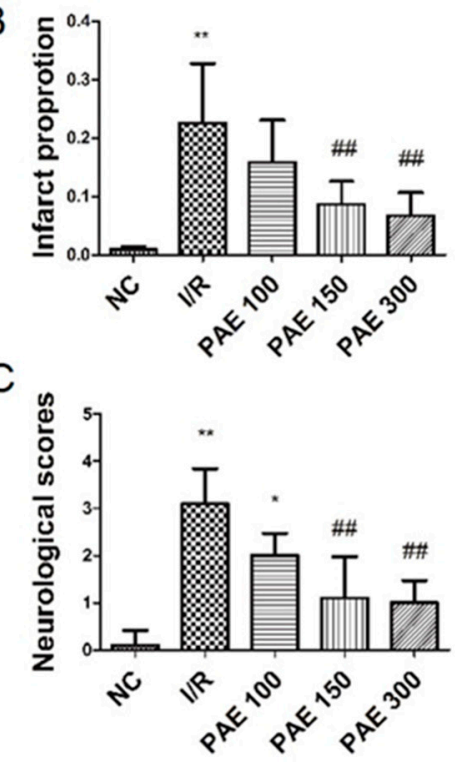

Figure 4. Effect of purified anthocyanin extracts (PAEs) from Dongkui Myrica rubra on neurological deficits and on cerebral infarct volumes in experimental mice (triphenyl tetrazolium chloride (TTC) stain, infarction remains unstained). The quantification of (A) is shown in (B); (C) neurological deficit scores. The data are expressed as mean $\pm \operatorname{SD}(n=10) ;{ }^{*} p<0.05,{ }^{* *} p<0.01$ vs. negative control (NC) group; ${ }^{\#} p<0.01$ vs. I/R group.

\subsection{Effect of PEAs on the NO, SOD, and MDA Contents in the Brains of Experimental Mice}

During cerebral ischemia, reperfusion, and recovery, multiple pathways are involved in the cascade of rapid injury, such as brain edema, excess free-radical formation, energy disruption, apoptotic gene activation, calcium overload, leukocytosis, and a series of pathological changes [18]. MDA and NO are involved during the cerebral I/R injury, while SOD is involved in preventing injury.

$\mathrm{NO}$ is a non-traditional neurotransmitter that is produced by NO synthase, which degrades arginine. NO inhibits normal mitochondrial energy production in many pathological processes, and it has a toxic response that leads to cell death [19]. In recent years, many studies confirmed that NO plays a key role in the pathogenesis of cerebral ischemia. Therefore, $\mathrm{NO}$ content in the brain tissue of mice directly reflects the extent of brain damage [20]. As shown in Figure 5, compared with the NC group, NO content was significantly higher in brain tissue from the I/R group $(p<0.01)$. However, in mice treated with PAE, NO content was significantly lower in brain tissue compared with the model group $(p<0.01)$. NO plays a very complex role in cerebral ischemia, and accordingly, the results reflect the different experimental conditions.
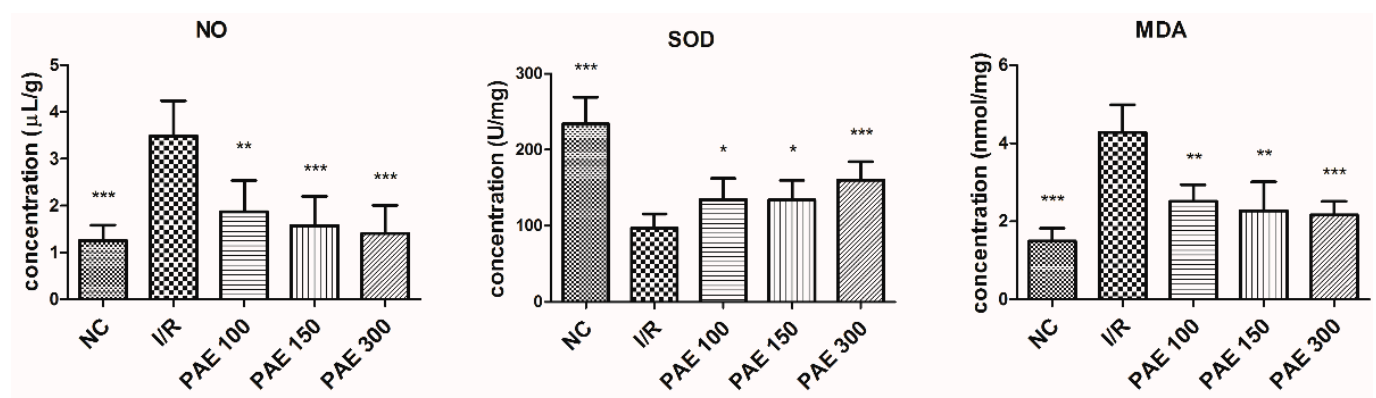

Figure 5. Effect of PAEs from Dongkui Myrica rubra on the nitric oxide (NO), malondialdehyde (MDA), and superoxide dismutase (SOD) contents in the brain tissue of mice with cerebral ischemia-reperfusion injury. The data are expressed as mean $\pm \operatorname{SD}(n=10){ }^{*} p<0.05,{ }^{* *} p<0.01,{ }^{* * *} p<0.001$ vs. I/R group. 
Excess free radicals can cause lipid, protein, and nucleic-acid peroxidation. Consequently, damaged membrane structures, and irreversible cell changes and death cause microcirculatory disturbances and increased blood-brain barrier permeability in brain tissue [21]. SOD is an effective free-radical scavenger, and an important antioxidant enzyme for scavenging oxygen free radicals in the body. Thus, SOD plays a significant role in oxidation and the antioxidant balance of the organism. Decreased SOD activity results in the accumulation of a large number of free radicals in the brain. Free radicals induce lipid peroxidation of cell membranes, resulting in damage to the structure and function of cell membranes, with resultant neuronal damage. SOD's capability as an oxygen free-radical scavenger is reduced upon increased consumption. Brain-tissue damage can lead to decreased SOD activity, increased levels of free radicals, and biofilm lipid peroxidation, resulting in large amounts of MDA. The MDA content reflects the oxygen free-radical content in the body, which reflects the extent of lipid peroxidation [20]. Our results show that PAE significantly prevents the decrease in SOD content and increase in MDA content in the brain tissue of mice $(p<0.01)$, which effectively improves cerebral I/R injury. Studies found that, after cerebral ischemia, blood flow is reconstructed with increased lipid peroxide levels in the brain and serum. Meanwhile, there is also increased tissue damage, and a greater level of lipid-peroxidation products and MDA [22].

\subsection{Effect of PAEs on Brain Pathology in Experimental Mice}

A pathological examination of brain tissue of mice from the NC group found normal cell structures, clear cell structures, normal cell morphologies, and clear edges, with uniform staining of the nucleus and intercellular substances. However, in mice from the I/R group, the histopathological examination revealed a sparse and disordered cell arrangement, vacuolar degeneration, cell-gap enlargement, blurring of membrane boundaries, nuclear pyknosis, contraction of cell bodies, and cellular degeneration and necrosis, as indicated by the arrows in Figure 6. Damaged brain tissue in mice treated with PAEs was not apparent, and the degree of injury in mice treated with a high dose of PAE was visibly reduced. This indicates that the extraction and purification of anthocyanin from Myrica rubra plays an important role in the protection of brain tissue (Figure 6).

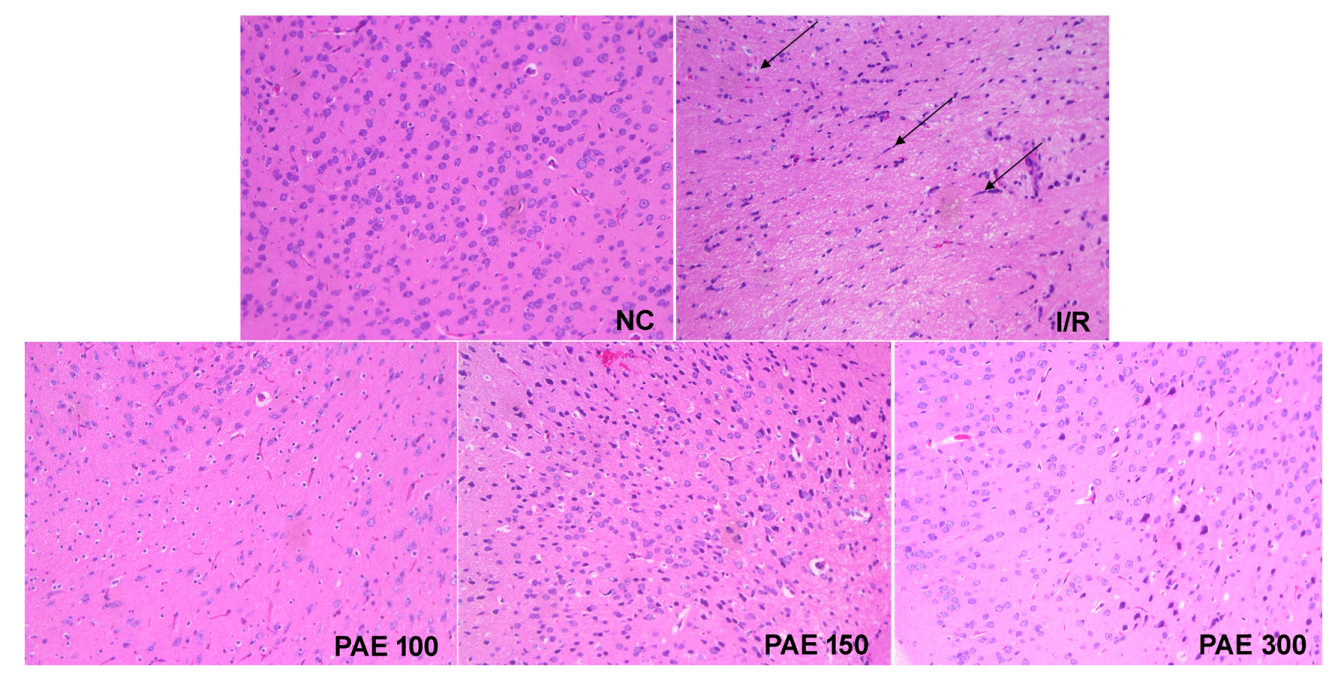

Figure 6. Effect of PAEs from Dongkui Myrica rubra on brain pathology in experimental mice (hematoxylin and eosin stain, $\times 200$ ). The images are from the same region of the brain under different experimental conditions.

\subsection{Effect of PAEs on the TLR4/NF-אB Signaling Pathway}

Inflammatory reactions, apoptosis, and calcium overload are the main causes of cerebral I/ $R$ injury $[23,24]$, with oxidative stress considered as one of the potential factors of ischemic injury. 
The brain needs and uses a lot of energy to function properly. With an increase in the rate of oxygen utilization, the unsaturated fatty-acid content in neural cell membranes increases, while antioxidant enzyme levels decrease, leading to vulnerability of the brain to oxidative stress [25]. A disrupted balance between oxidant and antioxidant processes is due to a breakdown of the antioxidant defense system, which is caused by the overproduction of reactive oxygen species. Reactive oxygen species destroy lipids, proteins, and nucleic acids, and alter the signaling pathways that cause cell death (necrosis or apoptosis) [25]. Therefore, antioxidants are often used as therapeutic agents for cerebral I/R injury [26]. Excitingly, anthocyanins are polyphenols that have strong antioxidant properties. As shown in Figure 7A,B, the protein expression levels of Toll-like receptor 4 (TLR4) and tumor necrosis factor $\alpha$ (TNF- $\alpha)$ in the brain tissue of mice from the I/R group were increased compared with those in that of mice from the NC group $(p<0.01)$. After PAE treatment, the expression of these proteins was reduced in the brain tissue when compared with that of the proteins in the I/R group, especially when treated with $300 \mathrm{mg} / \mathrm{kg}$ PAE ( $p<0.05)$. Immunohistochemical studies show that TLR4-positive cells gradually increase in the first 22 hours after I/R [27]. TLR4 can activate nuclear factor- $\kappa B$ (NF- $\kappa B$ ), ultimately causing an inflammatory response [28,29]. TLR4 also plays a key role in the pathological development of cerebral I/R injury [30], and TLR4 messenger RNAs (mRNAs) are upregulated in post-ischemic mouse brain tissue [31].

A
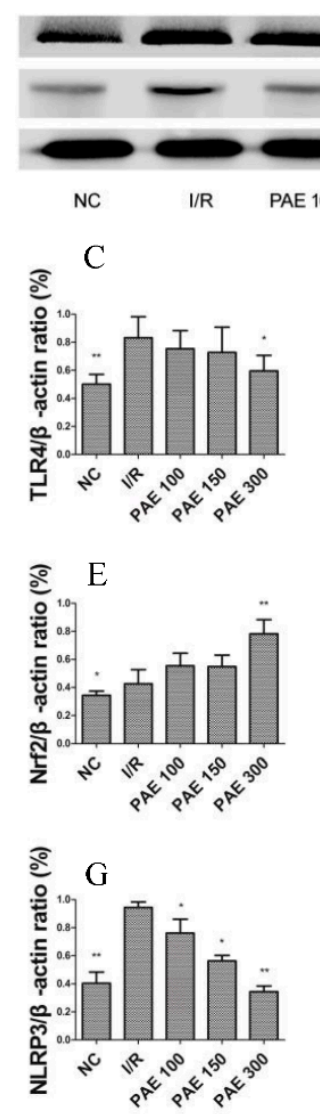

B

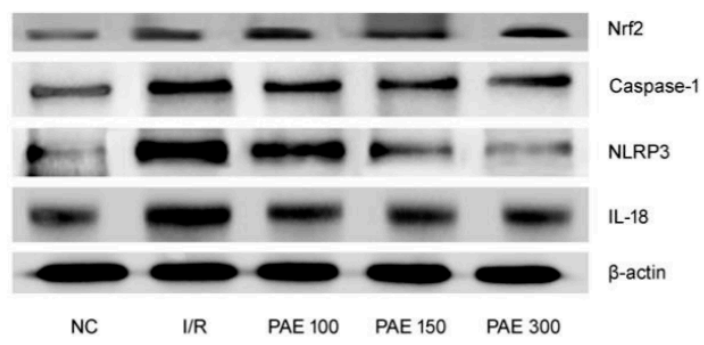

I

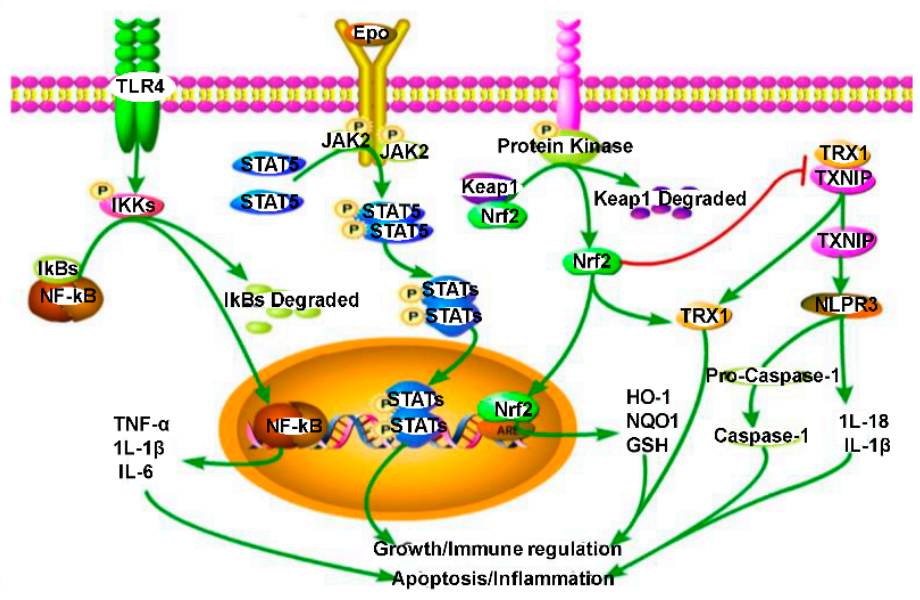

Figure 7. Effect of PAEs from Dongkui Myrica rubra on protein expression: (A) the expressions of Toll-like receptor 4 (TLR4), tumor necrosis factor alpha (TNF- $\alpha$ ), and $\beta$-actin; (B) the expressions of nuclear erythroid 2-related factor 2 (Nrf2), caspase-1, NOD-like receptor pyrin domain-containing 3 protein (NLRP3), IL-18, and $\beta$-actin. The quantifications of $(\mathbf{A})$ and $(\mathbf{B})$ are shown in $(\mathbf{C}-\mathbf{H})$. All of the data are shown as mean $\pm \operatorname{SD}(n=10) ;{ }^{*} p<0.05,{ }^{* *} p<0.01$ vs. I/R group. (I) The signal pathways; $\uparrow$ represents activation, while $\mathrm{T}$ (red line) represents inhibition. 


\subsection{Effect of PAEs on the NLRP3 Signaling Pathway}

Recent studies showed that the nuclear erythroid 2-related factor 2 (Nrf2) negatively regulates NLRP3 inflammasomes by regulating the thioredoxin-1/thioredoxin-interacting protein (TRX1/TXNIP) complex [32]. This complex inhibits caspase-1, IL-18, and IL-1 $\beta$ activation [33], thereby inhibiting apoptosis and inflammatory responses, protecting neurons, and reducing brain damage. Our research shows that PAE can significantly inhibit the expression of caspase-1, NLRP3, and IL-8, as well as activated Nrf2, in the brain tissue of I/R mice, thereby inhibiting inflammation and cell apoptosis, and protecting brain tissue. In addition, the regulatory effects of PAE were found to increase in a concentration-dependent manner (Figure 7).

Oxidative stress refers to the imbalance of oxidation and antioxidant activity in the body, which tends toward oxidation, causing the inflammatory infiltration of neutrophils, thereby increasing the secretion of protease and producing a large number of intermediate products of oxidation. Oxidative stress and TLR4 can activate NF- $\mathrm{KB}$, thereby promoting the gene expression of various inflammatory cytokines.

Anthocyanins simultaneously attenuate inflammatory responses and oxidative stress by activating the JAK2/STAT3 signaling pathway, thereby reducing heart and cerebral I/R injury [34-36] (Figure 7I).

In addition, it was found that anthocyanin can inhibit the degradation of I KB induced by LPS in BV-2 cells, and the nuclear translocation of NF- $\mathrm{kB}$ p65 in murine neuroglia cells, thus reducing the proinflammatory mediators, including the production of nitric oxide, prostaglandin E2, and proinflammatory cytokines such as IL-1 $\beta$ and TNF- $\alpha$ [37].

Polyphenols are very important substances for improving the structure and function of capillaries and vessels, and also for helping stimulate and improve the circulatory system. Anthocyanins, which have the effect of not being oxidized by free radicals, are the only antioxidants that have the ability to protect the brain cells from the blood-brain barrier, and to protect the brain from oxidation, as well as from harmful chemicals and toxins. Studies showed that foods with a high absorbance of oxygen free radicals can increase the level of antioxidants in the blood by $10-20 \%$ [38].

\section{Conclusions}

In conclusion, of the eight cultivated types of MR, the anthocyanin content in Boqi ${ }^{1}$ fruit was highest (as high as $22.07 \%$ ). In addition, through biochemical indices, and through macroscopic and microscopic observation of the brain tissue, we found that PAEs exert a beneficial protective effect against cerebral I/R. Furthermore, this protective effect may be related to the TLR4/NF- $k B$ and Nrf2/antioxidant responsive element (ARE) pathways. These results may provide a theoretical basis for daily life and clinical research.

Author Contributions: Data curation, H.-X.C. Investigation, J.-W.L. and F.-R.C. Methodology, H.-X.C. and J.-H.C. Project administration, K.Y. Software, J.-W.L. Writing—original draft, J.-W.L. Writing—review and editing, K.Y.

Funding: This project was sponsored by the Zhejiang Provincial Natural Science Foundation of China (LY13H280011).

Conflicts of Interest: The author claims that there are no conflicts of interest. All authors approved the final article.

\section{References}

1. Liu, Z.; Chen, X.; Gao, Y.; Sun, S.; Yang, L.; Yang, Q. Involvement of GluR2 up-regulation in neuroprotection by electroacupuncture pretreatment via cannabinoid CB1 receptor in mice. Sci. Rep. 2015, 5, 9490. [CrossRef] [PubMed]

2. Balami, J.S.; Chen, R.L.; Grunwald, I.Q.; Buchan, A.M. Neurological complications of acute ischaemic stroke. Lancet Neurol. 2011, 10, 357-371. [CrossRef]

3. Friedman, H.S.; Koroshetz, W.J.; Qureshi, N.; Marler, J.R.; Del Zoppo, G.J. Tissue plasminogen activator for acute ischemic stroke. N. Engl. J. Med. 1996, 334, 1405-1406. [CrossRef] [PubMed] 
4. Bueno, J.M. Analysis and Antioxidant Capacity of Anthocyanin Pigments. I. General Considerations Concerning Polyphenols and Flavonoids. Crit. Rev. Anal. Chem. 2012, 42, 102-125. [CrossRef]

5. Sun, C.D.; Huang, H.; Xu, C.J.; Li, X.; Chen, K.S. Biological Activities of Extracts from Chinese Bayberry (Myrica rubra Sieb. et Zucc.): A Review. Plant Foods Hum. Nutr. 2013, 68, 97-106. [CrossRef] [PubMed]

6. Li, Y.X.; Yang, Z.H.; Jia, S.S.; Yuan, K. Protective Effect and Mechanism of Action of Mulberry Marc Anthocyanins on Carbon Tetrachloride-Induced Liver Fibrosis in Rats. J. Funct. Foods 2016, 24, 595-601. [CrossRef]

7. He, Q.; Zhang, Z.F.; Zhang, L.G. Anthocyanin Accumulation, Antioxidant Ability and Stability, and a Transcriptional Analysis of Anthocyanin Biosynthesis in Purple Heading Chinese Cabbage (Brassica rapa L. ssp. pekinensis). J. Agric. Food Chem. 2016, 64, 132-145. [CrossRef] [PubMed]

8. Paulsmeyer, M.; Chatham, L.; Becker, T.; West, M.; West, L.; Juvik, J. Survey of Anthocyanin Composition and Concentration in Diverse Maize Germplasm. J. Agric. Food Chem. 2017, 26, 1-39. [CrossRef] [PubMed]

9. Huang, H.P.; Chang, Y.C.; Wu, C.H.; Hung, C.N.; Wang, C.J. Anthocyanin-rich Mulberry extract inhibit the gastric cancer cell growth in vitro and xenograft mice by inducing signals of p38/p53 and c-jun. Food Chem. 2011, 129, 1703-1709. [CrossRef]

10. Sun, C.; Zheng, Y.; Chen, Q.; Tang, X.; Jiang, M.; Zhang, J.; Li, X.; Chen, K. Purification and anti-tumour activity of cyanidin-3-O-glucoside from Chinese bayberry fruit. Food Chem. 2012, 131, 1287-1294. [CrossRef]

11. Bridle, P.; Timberlake, C.F. Anthocyanins as natural food colours-Selected aspects. Food Chem. 1997, 58, 103-109. [CrossRef]

12. Bederson, J.B.; Pitts, L.H.; Tsuji, M.; Nishimura, M.C.; Davis, R.L.; Bartkowski, H. Rat25 middle cerebral artery occlusion: Evaluation of the model and development of a neurologic examination. Stroke 1986, 17, 472-476. [CrossRef] [PubMed]

13. Yu, L.; Chen, C.; Wang, L.F.; Kuang, X.; Liu, K.; Zhang, H.; Du, J.R. Neuroprotective effect of kaempferol glycosides against brain injury and neuroinflammation by inhibiting the activation of NF- $\kappa \mathrm{B}$ and STAT3 in transient focal stroke. PLoS ONE 2013, 8, e55839. [CrossRef] [PubMed]

14. Fang, Z.X.; Zhang, M.; Wang, L.X.; Sun, J.C. Identification of anthocyanin in bayberry (Myrica rubra Sieb. et Zucc.) by HPLC-DAD-ESIMS and GC. J. Food Drug Anal. 2006, 14, 368-372.

15. Bravo, L. Polyphenols: Chemistry, dietary sources, metabolism, and nutritional significance. Nutr. Rev. 1998, 56, 317-333. [CrossRef] [PubMed]

16. Ross, J.A.; Kasum, C.M. Dietary flavonoids: Bioavailability, metabolic effects, and safety. Annu. Rev. Nutr. 2002, 22, 19-34. [CrossRef] [PubMed]

17. Tsuchidated, R. Regional cerebral blood flow during and after 2 hour middle cerebral artery occlusion in the rat. J. Cereb. Blood Flow Metab. 1997, 17, 1066-1073. [CrossRef] [PubMed]

18. Wang, B.; Wang, P.; Kang, J.; Lv, P.Y. Effects of dl-3n-butyphthalide on learning, memory and hippocampal NR2B expression in mice with vascular dementia. Chin. J. New Drugs 2008, 17, 43-46.

19. Fang, L.; Wang, N. Relationship between Nitric Oxide Synthase and Neuronal Damage at the Subacute Stage of Focal Cerebral Ischemia. J. Fujian Med. Univ. 2003, 37, 23-25.

20. Kader, A.; Frazzini, V.I.; Solomon, R.A.; Trifiletti, R.R. Nitric oxide production during focal cerebral ischemia in rats. Stroke 1993, 24, 1709-1716. [CrossRef] [PubMed]

21. Rosenberg, G.A. Ischemic brain edema. Prog. Cardiovasc. Dis. 1999, 42, 209-216. [CrossRef]

22. Yang, G.Y.; Schielke, G.P.; Gong, C. Expression of TNF2 $\alpha$ and ICAM21 after focal cerebral ischemia in IL2 $\beta$ converting enzyme deficient mice. J. Cereb. Blood Flow Metab. 1999, 19, 1109-1117. [CrossRef] [PubMed]

23. Ahmad, M.; Dar, N.; Bhat, Z.; Hussain, A.; Shah, A.; Liu, H.; Graham, S. Inflammation in Ischemic Stroke: Mechanisms, Consequences and Possible Drug Targets. CNS Neurol. Disord. Drug Targets 2014, 13, 1378-1396. [CrossRef] [PubMed]

24. Zhang, X.; Xue, X.; Xian, L.; Guo, Z.; Ito, Y.; Sun, W. Potential neuroprotection of protodioscin against cerebral ischemia-reperfusion injury in rats through intervening inflammation and apoptosis. Steroids 2016, 113, 52-63. [CrossRef] [PubMed]

25. Simonyi, A.; Wang, Q.; Miller, R.L.; Yusof, M.; Shelat, P.B.; Sun, A.Y.; Sun, G.Y. Polyphenols in Cerebral Ischemia. Mol. Neurobiol. 2005, 31, 135-147. [CrossRef]

26. Xu, Z.C.; Yin, J.; Zhou, B.; Liu, Y.T.; Yu, Y.; Li, G.Q. Grape seed proanthocyanidin protects liver against ischemia/reperfusion injury by attenuating endoplasmic reticulum stress. World J. Gastroenterol. 2015, 21, 7468-7477. [CrossRef] [PubMed] 
27. Tang, S.C.; Arumugam, T.V.; Xu, X.; Cheng, A.; Mughal, M.R.; Jo, D.G.; Lathia, J.D.; Siler, D.A.; Chigurupati, S.; Ouyang, X.; et al. Pivotal role for neuronal Toll-like receptors in ischemic brain injury and functional deficits. Proc. Natl. Acad. Sci. USA 2007, 104, 13798-13803. [CrossRef] [PubMed]

28. Cao, C.X.; Yang, Q.W.; Lv, F.L.; Cu, J.; Fu, H.B.; Wang, J.Z. Reduced cerebral ischemia reperfusion injury in Toll-like receptor 4 deficient mice. Biochem. Biophys. Res. Commun. 2007, 353, 509-514. [CrossRef] [PubMed]

29. Wang, C.P.; Shi, Y.W.; Tang, M.; Zhang, X.C.; Gu, Y.; Liang, X.M.; Wang, Z.W.; Ding, F. Isoquercetin Ameliorates Cerebral Impairment in Focal Ischemia Through Anti-Oxidative, Anti-Inflammatory, and Anti-Apoptotic Effects in Primary Culture of Rat Hippocampal Neurons and Hippocampal CA1 Region of Rats. Mol. Neurobiol. 2016, 29. [CrossRef] [PubMed]

30. Qi, W.; Zhou, F.; Li, S.; Zong, Y.; Zhang, M.; Lin, Y.; Zhang, X.; Yang, H.; Zou, Y.; Qi, C.; et al. Remote ischemic postconditioning protects ischemic brain from injury in rats with focal cerebral ischemia/reperfusion associated with suppression of TLR4 and NF-KB expression. Neuroreport 2016, 27, 469-475. [CrossRef] [PubMed]

31. Wang, P.F.; Fang, H.; Chen, J.; Lin, S.; Liu, Y.; Xiong, X.Y. Polyinosinic-polycytidylic acid has therapeutic effects against cerebral ischemia/ reperfusion injury through the down regulation of TLR4 signaling via TLR3. J. Immunol. 2014, 192, 4783-4794. [CrossRef] [PubMed]

32. Hou, Y.H.; Wang, Y.T.; He, Q.; Li, L.Y.; Xie, H.; Zhao, Y.; Zhao, J. Nrf2 inhibits NLRP3 inflammasome activation through regulating Trx1/TXNIP complex in cerebral ischemia reperfusion injury. Behav. Brain Res. 2018, 336, 32-39. [CrossRef] [PubMed]

33. Donnan, G.A.; Fisher, M.; Macleod, M.; Davis, S.M. Stroke. Lancet 2008, 371, 1612-1623. [CrossRef]

34. Luo, L.N.; Yang, P.; Huang, W. The effect and mechanism of anthocyanin on hepatic ischemia reperfusion injury in rats. J. Xian Jiaotong Univ. 2016, 4. [CrossRef]

35. Shin, W.H.; Park, S.J.; Kim, E.J. Protective effect of anthocyanins in middle cerebral artery occlusion and reperfusion model of cerebral ischemia in rats. Life Sci. 2006, 79, 130-137. [CrossRef] [PubMed]

36. McGhie, T.K.; Martin, H.; Lunken, R.C.M. The combination of analytical-scale HPLC separation with a TR-FRET assay to investigate JAK2 inhibitory compounds in a Bovsen berry drink. Food Funct. 2012, 3, 1170-1175. [CrossRef] [PubMed]

37. Jeong, J.W.; Lee, W.S.; Shin, S.C. Anthocyanins dowmnregulate lipopolysaccharide-induced inflammatory responses in BV2 microglial cells by suppressing the NF-kappaB and Akt/MAPKs signaling pathways. Int. J. Mol. Sci. 2013, 14, 1502-1515. [CrossRef] [PubMed]

38. Sun, Z.M.; Zhou, X.; Zhang, J.L.; Li, T. Research Progress of Anthocyanin Antioxidant Function in Aronia melanocarpa. Food Res. Dev. 2017, 38, 220-224. [CrossRef]

Sample Availability: Samples of the anthocyanin of Myrica rubra are available from the authors.

(C) 2018 by the authors. Licensee MDPI, Basel, Switzerland. This article is an open access article distributed under the terms and conditions of the Creative Commons Attribution (CC BY) license (http:/ / creativecommons.org/licenses/by/4.0/). 